\title{
Palladium Nanoparticles Synthesized by Pulsed Electrolysis in Room-Temperature Ionic Liquid
}

\author{
Gwangwon Park ${ }^{1}$,Jesik Park ${ }^{1}$, YoungjuCho ${ }^{2}$, Churl KyoungLee $e^{1, *}$ \\ ${ }^{1}$ School of Material Science \& Engineering, Kumoh National Institute of Technology, Gumi, \\ Gyungsangbuk-do 730-701, Republic of Korea \\ ${ }^{2}$ R\&D Center for Valuable Recycling, Daejeon, Republic of Korea \\ "E-mail: cklee@kumoh.ac.kr
}

doi: $10.20964 / 2016.06 .62$

Received: 3 March2016 / Accepted: 30 March 2016 / Published: 4 May 2016

Synthesis of palladium nanoparticles by pulsed electrolysis was investigated in the room-temperature ionic liquid 1-butyl-3-methylimidazolium chloride $\left(\left[\mathrm{C}_{4} \mathrm{mim}\right] \mathrm{Cl}\right)$ using palladium chloride $\left(\mathrm{PdCl}_{2}\right)$ as the palladium source. A palladium-coated carbon $(\mathrm{Pd} / \mathrm{C})$ catalytic electrode was synthesized by direct deposition of palladium on a carbon paper working electrode. The size and distribution of the palladium particles were easily controlled by varying the electrolysis conditions such as the overpotential, holding time of the applying potential, and temperatures. The composition, crystal structure, and morphology of the palladium were confirmed by scanning electron microscopy combined with energy dispersive spectroscopy and transmission electron microscopy. The uniformly distributed palladium nanoparticles had an average size of $3.6 \mathrm{~nm}$ with a standard deviation of 0.4.

Keywords: palladium, ionic liquid, pulse, electrolysis, nanoparticle

\section{$\underline{\text { FULL TEXT }}$}

(C) 2016 The Authors.Published by ESG (www.electrochemsci.org). This article is an open access article distributed under the terms and conditions of the Creative Commons Attribution license (http://creativecommons.org/licenses/by/4.0/). 